UDC 304.4

LBC 60.59

\title{
BETWEEN TECHNOLOGY AND INSTITUTIONS: FEATURES OF FORMING E-GOVERNMENT IN VOLGOGRAD REGION ${ }^{1}$
}

\author{
Elena G. Vasileva \\ Volgograd State University, Volgograd, Russian Federation
}

\begin{abstract}
The author analyzes the processes of development of e-Government in the Volgograd region taking into account the transformation of global strategies for its evaluation and the increasing importance of participatory social interaction. The analysis is based on the data of sociological surveys of Volgograd residents, the results of a formal assessment of the information infrastructure of the regional e-Government, the synthesis of state statistics and statistics of the regional portal of state and municipal services conducted in 2015-2017.

The structure of this research paper includes the justification of methodological guidelines for the study of local e-Government practices, description of the main stages, features and results of the introduction of e-Government technology in the Volgograd region, the analysis of institutional problems of its development.

E-Government is considered in the context of three methodological postulates: the idea of e-Government as the best governance (e-Participation); the idea of e-Governance as a set of socio-managerial and technological innovations that ensure the benefits of informatization and digitalization for the public good; the idea of e-Government as a tool / mechanism for the development of e-Democracy and support for social initiatives and projects based on participatory interaction.

Local e-Government practices are considered as management practices and actions; as decisions aimed at implementing social and technological innovations and emerging under the influence of global and national strategy; as the content of administrative policies of the executive authorities of the region and municipalities related to strategic and current management tasks. Depending on the management policy and the results of its implementation the author defines and distinguishes three stages in the development of regional e-Government and common features of the process. These features include: priority development of areas related to the formation of information infrastructure and electronic public and municipal services; mobilization type of implementation of social and managerial innovations; the prevalence of "vertical integration" over "horizontal contingence" and organizational and managerial decisions over strategic decisions. In general, the electronic government of the Volgograd region is "e-Government for the population", and "e-Government for business" is just beginning to form.
\end{abstract}

Key words: e-Government, e-Participation, e-Services, digital development index, participatory interaction.

УДК 304.4

ББК 60.59

\section{МЕЖДУ ТЕХНОЛОГИЕЙ И ИНСТИТУТАМИ: ОСОБЕННОСТИ ФОРМИРОВАНИЯ ЭЛЕКТРОННОГО ПРАВИТЕЛЬСТВА В ВОЛГОГРАДСКОЙ ОБЛАСТИ ${ }^{1}$}

\author{
Елена Геральдовна Васильева
}

Волгоградский государственный университет, г. Волгоград, Российская Федерация

Аннотация. В данной статье анализируются процессы развития электронного правительства (e-Government)
в Волгоградской области с учетом трансформации глобальных стратегий его оценки и возрастания значимо-
сти партисипативного социального участия. Анализ основан на результатах социологических опросов жите-
лей Волгограда, проведенных в $2015-2017$ гг. (в том числе результатах формализованной оценки информаци-
онной инфраструктуры регионального электронного правительства), на данных государственной статистики 
и статистики регионального портала государственных и муниципальных услуг, . Структура данной работы включает обоснование методологических ориентиров для исследования локальных практик электронного правительства, описание основных этапов, особенностей и результатов внедрения технологии электронного правительства в Волгоградской области, анализ институциональных проблем его развития.

Электронное правительство рассматривается в контексте трех методологических постулатов: идеи электронного правительства (e-Government) как лучшего управления (e-Participation); идеи электронного управления как совокупности социально-управленческих и технологических инноваций, обеспечивающих использование преимуществ информатизации и цифровизации для общественного блага; идеи электронного государственного управления как инструмента / механизма развития электронной демократии и поддержки социальных инициатив и проектов, основанных на партисипативном участии.

Локальные практики электронного правительства рассматриваются как практики управления и действия; как решения, направленные на внедрение социально-технологических инноваций и формирующиеся под влиянием глобальной и общегосударственной стратегии; как содержание административных политик органов исполнительной власти региона и муниципалитетов, связанных со стратегическими и текущими задачами управления. В зависимости от управленческой политики и результатов ее реализации разграничиваются три этапа в развитии регионального электронного правительства и выявляются общие особенности процесса. Данные особенности включают: приоритетное развитие направлений, связанных с формированием информационной инфраструктуры и электронными государственными и муниципальными услугами; мобилизационный тип внедрения социально-управленческих инноваций; преобладание «вертикальной интеграции» над «горизонтальной связанностью» и организационно-управленческих решений над стратегическими решениями. В целом электронное правительство Волгоградской области является «электронным правительством для населения», а «электронное правительство для бизнеса» только начинает формироваться.

Ключевые слова: электронное правительство, электронное участие, электронные услуги, индекс цифрового развития, партисипативное участие.

\section{Введение}

Электронное правительство соотносится с областью социально-технологических инноваций, направленных на рационализацию управления, развитие сервисного государства и культуры партисипативной демократии, а также на использование преимуществ цифровизации и сетевой коммуникации в целях устойчивого экономического развития и создания общественных благ. Практическое внедрение инноваций связано с преодолением инерционности систем социального действия - противоречия «технологий и институтов (ценностей)», которое влияет на реализацию стратегических политик и принимаемые организационно-управленческие решения локального уровня.

В данной статье представлены результаты социологического исследования практики внедрения электронных государственных и муниципальных услуг в Волгоградской области, а также анализируются особенности и перспективы регионального электронного правительства исходя из приоритетов государственных целевых программ его раз- вития и ориентиров глобальной стратегической оценки.

\section{Методология и методы}

Концептуальные рамки анализа определяются инструментальным подходом, разграничивающим понятия электронного правительства (e-Government) и электронного управления (e-Governance) [Sakowicz web; Bannister, Connolly 2012; Palvia, Sharma web] и ориентированным на рационализацию модели социального участия [Porwol, Ojo, Breslin 2016]. Тенденции развития электронного правительства отражаются в изменении направлений и структуры показателей его оценки, реализуемой международными институтами развития, которые определяют методологию различных программ его оценки [World Development Report 2016; The United Nations... web].

При исследовании локальных практик формирования регионального электронного правительства не всегда возможен расчет глобальных стратегических индексов вследствие ограниченности статистических данных [Борисова 2014, 94-102], а кроме того, 
возникает проблема интегральных показателей оценки и обозначается недостаточность количественных методов для выявления социальных эффектов нововведений и связанных с ними институциональных изменений. Исходя из этого, исследование определялось задачей комплексного анализа ситуации на основе систематического описания процесса управления и действия (решений, проектов, инициатив).

При обобщении и анализе социально-технологических инноваций и организационно-управленческих решений, связанных с региональным электронным правительством, использовались исследования влияния программных технологий на управленческие модели [Акаткин, Дрожжинов, Конявский 2014]; оценки проблем реализации стратегической программы развития электронного правительства в РФ [Павлюченкова 2013; Данилина, Багратуни 2015; Пясецкая web]; учитывались результаты исследований особенностей процессов информатизации в Волгоградской области [Калинина, Шевандрин 2012].

При сборе данных использовались методы статистического наблюдения и анкетного опроса, исследовательские категории соотносились с показателями стратегических моделей оценки (техническая оснащенность, развитие государственных электронных услуг, возможности социального участия). Проводилось тестирование электронных сервисов (июнь - июль 2016 г.), в качестве объекта наблюдения выступали информационные интернет-ресурсы, соотносящиеся с инфраструктурой электронного правительства Волгоградской области (3 базовые платформы - региональный портал государственных и муниципальных услуг, сеть «Мои документы», портал губернатора Волгоградской области; 30 муниципальных сайтов; 5 специализированных информационных ресурсов). Кроме того, в течение 2016 г. проводилось статистическое обобщение информации, размещаемой на региональном портале государственных и муниципальных услуг. При анализе характеристик социального участия использовались результаты социологических опросов, выявляющих отношение к единому порталу государственных и муниципальных услуг, в том числе анкетирование жителей Волгограда (2015 г.,
$N=750$ чел., тип выборки - целенаправленная, районированная, с использованием квотно-маршрутного метода отбора по признакам пола, возраста) и анкетирование молодежи (2017 г., $N=100$ чел., тип выборки - целенаправленная, гнездовая, с использованием методов сплошного отбора в учебных группах Волгоградского государственного университета). При исследовании практик формирования электронного правительства также использовались данные государственной и ведомственной статистик [Лайкам и др. 2017; Абдрахманова и др. 2017].

\section{Электронное правительство как идея: стратегический дискурс и ценности}

Современная управленческая стратегия в отношении электронного правительства определяется преимущественно тремя группами факторов: программными оценками, формируемыми глобальными институтами развития на основе межстрановых сравнительных исследований; моделями технологической направленности, формируемыми в междисциплинарном пространстве социальной информатики (теории систем, управления и программирования); политиками его практического внедрения, отражаемыми в национально-государственных (правительственных) программах.

Первая группа влияний создает общий социальный и стратегический дискурс, связанный с идеями «наилучшего» управления в целях общественного развития и эффективности систем действия в условиях информационного общества и экономики знаний. Изменения в комплексном подходе к пониманию электронного правительства связаны с акцентировками «электронного управления» или «электронной демократии» и определяются переходом от консолидированной модели централизованных, иерархических и работающих в тесном сетевом взаимодействии управленческих систем - к новой модели управления, основанной на самоорганизующихся межорганизационных (interorganisational) сетях обмена местных и глобальных знаний в цифровой экономике [Sakowicz web].

Данная тенденция отражается и в дифференциации показателей глобальной про- 
граммной оценки. На первоначальном этапе электронное правительство концептуализировалось преимущественно в аспекте информатизации и информирования, а также совершенствования процессов государственного управления. Его влияние оценивалось исходя из использования ИКТ, возможностей доступа для населения и развития электронных государственных услуг и сервисов [Framework... web]. В последующем усилилась тенденция его интерпретации в более широком спектре отношений - взаимодействия государства и бизнеса, бизнеса и населения, государства и НКО, а также взаимовлияния технологий и институтов (ценностей), инноваций (компетенций, знаний) и результатов (общественных благ, производительности и занятости, экономического роста). В целом оценка стала менее технологической и более институциональной, учитывающей расширение возможностей социального участия в целях эффективного управления, устойчивого развития и общественной пользы [World Development Report 2016].

\section{Электронное правительство}

\section{как технология: целевые приоритеты}

Вторая группа влияний связана с технологическими аспектами электронного правительства и представлена в моделях «объединенного / связанного / сетевого /мобильного / умного правительства», которые сформировались под значительным влиянием практики («языка») IT-проектов и отражают различные подходы к проектированию информационно-программной среды. В общем плане данные модели отражают переход от вертикальных информационно-управляющих систем к горизонтальным, связанным, сетевым проектам, от однонаправленного информирования к многоцелевому контенту и интерактивному взаимодействию и от электронного управления к электронным сервисам. Например, в критерии для оценки электронных сервисов с учетом целей социального участия включаются индикаторы, характеризующие содержательные аспекты коммуникации (уровень демократии, возможности гражданского участия, права человека и возможности; общественное само- управление), технические аспекты их представления в среде Интернет (единый портал, все публичные сервисы предоставляются в электронном виде, функции поиска, простая навигация, возможность электронных платежей), а также социально-управленческие аспекты (возможность обратной связи, неограниченные возможности доступа и получения отзыва, приватность и безопасность, легальность поддержки, ориентация на потребителей) [Palvia, Sharma web].

Социальные функции технологии электронного правительства связаны с формированием новых структур и институциональных порядков коммуникации, которые становятся важными для эффективного управления и вместе с тем приобретают значение новых соииальных правил действия. Так, «умное правительство» отражает уже не столько программно-технологические, сколько социально-управленческие аспекты понимания электронного правительства: технологии и инфраструктура умного правительства «интегрируют информацию, потребителей услуг и операционные технологии правительства в ходе выполнения им функций государственного планирования, менеджмента и оперативного управления, невзирая на функциональные домены, области процессов и юрисдикции, в целях генерации устойчивых общественно значимых ценностей (благ)» [Акаткин, Дрожжинов, Конявский 2014, 65].

Данные аспекты характеризуют электронное правительство с точки зрения создания социально-управленческих инноваций и соотносятся с действующей стратегией и практической политикой по его внедрению. Эксперты Всемирного банка определяют указанные инновации как «дивиденды цифровизации» и рассматривают их в контексте разрешения противоречия «между технологиями и институтами» в условиях возрастающих рисков использования преимуществ цифрового управления для контроля над обществом и усиления давления со стороны элит. Принимаемые решения определяют своеобразие и успешность национально-государственных стратегий и локальных проектов реализации электронного правительства. 


\section{Электронное правительство}

В Волгоградской области: этапы и особенности формирования

Развитие региональных практик электронного правительства в России определяется федеральной стратегией формирования его общей инфраструктуры и представлено в завершенных и действующих государственных целевых программах «Электронная Россия» (2002-2010 гг.), «Информационное общество» (2011-2020 гг.), «Цифровая экономика Российской Федерации» (2018-2024 гг.). Исходя из задач и достигнутых результатов данных программ (массовая информатизация - переход к государственным и муниципальным электронным услугам - развитие цифровой экономики), а также их научного анализа и экспертной дискуссии [Павлюченкова 2013; Данилина, Багратуни 2015; Пясецкая web], можно сказать, что государственная политика Российской Федерации соответствует в большей мере стратегическому дискурсу «от эффективного управления и сервисного государства - к сетевому правительству для граждан и бизнеса» [Васильева, Кононенко 2017$].$

Специфика региональной практики может быть охарактеризована через особенности управленческого процесса как процесса внедрения технологических и социальных инноваций [Калинина, Шевандрин 2012]. Основываясь на показателях развития инфраструктуры электронного правительства (прежде всего информационной среды и электронных сервисов), а также учитывая организационноуправленческие влияния и фактически внедренные инновации, можно выделить следующие периоды развития электронного правительства в Волгоградской области: 20072012 гг. - начальный этап развития (создание действующей системы электронного документооборота и информирования населения о деятельности органов власти); 2013-2016 гг. этап создания базовой инфраструктуры электронного правительства (единой региональной справочно-информационной системы и регионального портала государственных и муниципальных услуг); с 2017 г. по настоящее время - переход к связанному электронному правительству (создание дополнительных государственных информационных систем и он- лайн-сервисов для населения, развитие направления «государство - бизнес»).

Характеризуя особенности процесса, необходимо отметить, что реализация проекта электронного правительства началась вместе с разработкой и принятием региональной Концепции информатизации (2007-2011гг.) [Постановление Главы Администрации Волгоградской области от 26.10.2011 ... web], определившей его перспективу как создание системы межведомственного документооборота, региональной информационно-справочной системы, системы планирования регионального бюджета и системы электронных государственных услуг. Фактически приоритетным направлением стала техническая и программная информатизация управленческих процессов, а наиболее важным результатом - межведомственная система электронного документооборота, обеспечившая прозрачность системы отчетности. В целом внедряемые инновации носили локальный (несистемный) характер, а созданная инфраструктура служила в первую очередь целям ведомственного учета (показательно, что в 2012 г. в региональных СМИ появилась критика областного Комитета информационных технологий, основанная на результатах проверки его деятельности Контрольно-счетной палатой Волгоградской области).

В последующий период внедрение инноваций определялось трансформацией властных функции в комплексы услуг для населения и созданием информационных баз данных как элементов инфраструктуры электронного правительства. На уровне управленческой практики это проявилось, прежде всего, как регламентация комитетами областной администрации перечня услуг и процедур их предоставления, их «подключение» к процессам структурирования и «наполнения» информационным контентом регионального портала государственных и муниципальных услуг, а также создание и администрирование специализированных информационных систем в целях информирования и взаимодействия при реализации функций управления.

В целом процессы технологизации услуг отличались значительной неравномерностью. Так, на начало 2016 г, по данным официального сайта Губернатора и Администрации Вол- 
гоградской области, из 29 структурных подразделений региональной исполнительной власти регламентировали услуги для населения 22 областных комитета /инспекции; при этом 12 комитетов регламентировали в качестве услуг не менее 5 видов деятельности, а ряд комитетов - от 20 и до 55 услуг (комитеты по социальной защите населения, по сельскому хозяйству, по природе и экологии, по труду и занятости и др.). Кроме того, 10 структурных подразделений указывали в качестве направления деятельности ведение одной-двух информационных систем. В то же время следует отметить, что, несмотря на регламентацию перечня муниципальных услуг в областном законодательстве еще в 2013 г. [Постановление Правительства Волгоградской области от 27.05.2013... web], «массовое подключение» муниципалитетов к региональному порталу было проведено только в 2015-2016 годах.

Начиная с 2016 г., прежде всего, вместе с созданием институциональной подсистемы МФЦ (в течение 2016 г. число МФЦ выросло в три с лишним раза - с 7 до 24 единиц), можно говорить о создании «работающего» регионального электронного правительства типа «государство - население». Это обеспечивалось качественно новым уровнем инфраструктуры (на основе каталогизации услуг в соответствии с запросами потребителей; расширения спектра услуг; роста числа муниципалитетов, зарегистрированных в реестре) и совершенствованием электронных сервисов (преимущественно за счет совмещения регионального портала с единым государственным порталом услуг, которое обеспечивало качество услуг, соотносимое с международными стандартами оценки, - «услуги электронного взаимодействия» и «объединенные услуги»). Кроме того, развитию инфраструктуры способствовал целый ряд инноваций, связанных с развитием дополнительных сервисов, внедренных в 2017-2018 гг. и соотносящихся со связанным, то есть более продвинутым, уровнем электронного правительства (онлайн-сервисы «Электронная регистратура», «Запись в детский сад / первый класс», «Транспорт», «Образование», «Здравоохранение» и др.), а также качественно иной, более технологичный и современный дизайн представления информационных ресурсов на официальном портале органов исполнительной власти Волгоградской области и в единой региональной справочно-информационной системе.

Одна из наиболее важных особенностей процесса состоит в том, что внедрение электронных государственных и муниципальных услуг в Волгоградской области определялось в первую очередь федеральным законодательством, устанавливающим перечень приоритетных (для оказания в электронной форме) услуг, которые соотносились преимущественно с полномочиями федеральных исполнительных структур власти и включали лишь общие направления региональных и муниципальных услуг. В этой связи необходимо подчеркнуть, что динамика и результативность внедрения социально-управленческих инноваций в значительной, если не в полной мере определялись административным, методическим и контролирующим влиянием федеральных структур управления (показательно, что введение федерального мониторинга качества услуг значительно ускорило процессы формирования информационного контента и реестра услуг).

Важной особенностью процесса является и то, что решения, связанные с электронным правительством, реализуются как организационно-управленческие, а не стратегические решения. На первоначальных этапах электронное правительство воспринималось в качестве технической, а не социально-управленческой инновации - как задача «для программистов», а не «для общества и государства». «Проблема компетенций» связывалась преимущественно с необходимостью проектирования ограниченных информационно-управляющих систем, а не с перспективой законодательно-нормативного разграничения властных полномочий и функций, а также регламентацией государственных и муниципальных функций как услуг.

В целом создание информационной инфраструктуры для регионального электронного правительства обеспечивалось скорее на основе организационно-административных методов, чем на основе стратегической координации практик муниципального и регионального управления, а также анализа практик взаимодействия с населением. 


\section{Электронное правительство}

В Волгоградской области: противоречия технологии и институтов

Можно предположить, что доминирующая практика принятия управленческих решений способствует формированию противоречий между технологической и институциональной сторонами внедрения социальных инноваций, связанных с электронным правительством. В свою очередь, это создает риски нивелирования ценностного содержания «электронного правительства для населения».

Данные аспекты были проанализированы в рамках обобщения основных изменений в практиках деятельности, связанных с функционированием электронного правительства.

Обращение к статистике регионального портала государственных и муниципальных услуг (наблюдение велось в течение 2016 г.) оказалось информативным только в отношении «предложения» услуг, которое, по данным наблюдения, за полгода выросло на одну треть: так, в июне 2016 г. в базе данных регионального портала содержались информационные сведения о 5094 услугах, а в ноябре 2016 г. о 7325 услугах. В среднем число задекларированных услуг составило в городских муниципальных округах 60 единиц, в районных муниципалитетах -43 единицы, а в сельских муниципальных образованиях (поселениях) 10 единиц.

Анализ изменений в информационных базах данных, представленных на региональном портале (с июня по октябрь 2016 г.), позволил зафиксировать следующие особенности: каталогизация услуг определялась управленческим функционалом (в последующем появилась дополнительная возможность поиска - «услуги по жизненным ситуациям», которая в большей мере отвечала запросам потребителей); категории структурирования информации определялись задачами отчетности, связанными с подготовкой сведений для реестра услуг и «наполнения» информационных баз федерального и регионального портала (соответствовали сферам функциональной деятельности исполнительных структур областной администрации, определяющих перечень услуг и отвечающих за разработку административных регламентов); информация о муниципальных услугах воспроизводилась «по шаблону» и была ориентирована на количество услуг, позволяющих улучшить общие показатели статистики муниципального района / регионального портала (в отдельных сельских поселениях число предоставляемых услуг в 2 раза превышало число услуг муниципалитета города Волгограда).

Результаты тестирования структуры и численности услуг, представленных на региональном портале на ноябрь 2016 г., подтверждают общую тенденцию роста муниципальных услуг, доля которых составила $91 \%$ (см. табл. 1, 2).

Численность услуг по категориям «Имущественные отношения», «ЖКХ», относящиеся к муниципальным услугам, также подтверждает указанную тенденцию. Кроме того, обращает на себя внимание то, что значительную долю региональных услуг составляют услуги социальной сферы (категории «Социальное обеспечение», «Семья»), услуги, связанные с информированием населениях («Культура»). Следует отметить, что в среднем $28 \%$ услуг, информация о которых размещалась на сайте, декларировались как электронные услуги. Фак-

Таблииа 1

Виды услуг (по полномочиям), представленных на региональном портале государственных и муниципальных услуг Волгоградской области (ноябрь 2016 г.)

\begin{tabular}{|l|c|c|}
\hline \multicolumn{1}{|c|}{ Виды услуг } & Кол-во услуг & \% от общего числа услуг \\
\hline Региональные услуги & 428 & 6 \\
\hline Муниципальные услуги & 6651 & 3 \\
\hline Вневедомственные фонды & 246 & 100 \\
\hline
\end{tabular}

Примечание. Составлено автором на основе систематизации статистических данных, содержащихся на региональном портале государственных и муниципальных услуг. 
тически, если это соотносилось с муниципальными услугами, то речь шла о начальном уровне электронных сервисов (исходя из показателей мониторинга качества электронных услуг Министерства экономического развития, где фиксируется 5 этапов их внедрения) или о предоставлении сведений об услуге. Большинство региональных электронных услуг соотносилось на тот период со вторым уровнем (предоставление сведений, включающих образцы документов), а «зеленая кнопка» действовала только для услуг, относящихся к категориям приоритетных и услуг по переданным полномочиям [Васильева, Гаврилова 2017].

Следует отметить, что с учетом перехода к электронным государственных услугам федеральных структур, а также возможностей портала «Госуслуги.ру» (в который интегрировался региональный портал государственных и муниципальных услуг) были достигнуты значительные результаты по показателям вовлеченности населения во взаимодействие. На это указывают и данные всероссийского опроса по показателям развития информационного общества и цифровой экономики (2016 г.): по уровню развития
ИКТ показатели Волгоградской области оказываются близкими к среднестатистическим значениям, а численность населения, использующего официальные сайты и портал государственных и муниципальных услуг значительно возросла в 2016 г. по сравнению с 2015 г. (с 17,3 \% до 31,2 \%). В то же время, как показывают данные, при получении услуг взаимодействие осуществляется в большей степени через МФЦ, а социальные инновации, связанные с технологией электронного правительства (получение личной электронной подписи, регистрация на портале) и доля получателей электронных государственных и муниципальных услуг с использованием Интернета представлены значительно более низкими, в сравнении со средними, значениями (табл. 3,4 ).

Следует заметить, что относительно благополучная позиция России в сравнении с другими странами в развитии электронного правительства связана с показателями индекса развития электронного правительства ООН (прежде всего по индикаторам технической оснащенности и доступа, а также развития электронных сервисов и направлений элект-

\section{Категории услуг (по функциональному содержанию), представленных на региональном портале государственных и муниципальных услуг Волгоградской области (ноябрь 2016 г.)}

\begin{tabular}{|l|c|c|}
\hline \multicolumn{1}{|c|}{ Категории услуг } & $\begin{array}{c}\text { Доля услуг } \\
\text { в общем числе услуг, } \%\end{array}$ & $\begin{array}{c}\text { Доля декларируемых электронных услуг } \\
\text { в числе услуг по категории, \% }\end{array}$ \\
\hline Пенсионное обеспечение & 0,3 & 17 \\
\hline Наука & 0,4 & 7 \\
\hline дравоохранение & 0,6 & 14 \\
\hline Налоги и сборы & 0,8 & 15 \\
\hline Гражданство & 0,9 & 23 \\
\hline Спорт и туризм & 1,1 & 3 \\
\hline Труд и занятость & 1,7 & 7 \\
\hline Правопорядок и безопасность & 1,8 & 10 \\
\hline Транспорт & 2,0 & 17 \\
\hline Образование & 4,1 & 30 \\
\hline Производство и торговля & 4,4 & 2 \\
\hline Семья & 6,4 & 43 \\
\hline Культура & 8,3 & 36 \\
\hline Социальное обеспечение & 9,1 & 33 \\
\hline ЖКХ & 11,4 & 28 \\
\hline Имущественные отношения & 46,6 & 2 \\
\hline
\end{tabular}

Примечание. Составлено автором на основе систематизации статистических данных, содержащихся на региональном портале государственных и муниципальных услуг. 
ронного государства, связанных с предоставлением и охватом населения онлайновыми государственными услугами [Россия... web].

Управленческая практика указывает на то, что в развитии электронного правительства преобладали принципы «вертикальной интеграции» в сравнении с принципами «горизонтальной связанности», которые соотносятся с «традиционным» управленческим принципом принятия решений. Электронное правительство в этом случае ориентировано на рационализацию государственного управления на основе «наращивания» технологической составляющей - преимущественного развития информационно-коммуникационных технологий и их использования для прозрачности и подконтрольности действий исполнительных структур власти (в сравнении, например, с сетевой социальной информационной коммуникацией, партисипативным и стейкхолдерским участием).
Доминирование «технологий над институтами» также определялось особыми институциональными условиями: формирование информационной инфраструктуры электронного правительства в РФ шло одновременно с административной реформой государственного и муниципального управления. Достижение результатов во многом обеспечивалось однонаправленной мобилизацией и концентрацией технологических и управленческих ресурсов. В этой связи показательны результаты экспертной оценки значимости проблем, возникающих в процессе внедрения технологии в структурах государственной исполнительной власти: в качестве основных проблем называются организационно-управленческие недостатки, в том числе влияющие на информационное программирование (нереальность сроков исполнения работ, несогласованность процесса внесения изменений в правовую базу, рассогласование IT-стандартов и практик ре-

Тенденции развития электронного правительства в Волгоградской области Таблица 3 по некоторым показателям цифровой экономики (2016 г.)

\begin{tabular}{|l|c|c|c|}
\hline \multicolumn{1}{|c|}{ Индикаторы цифровой экономики } & $\begin{array}{c}\text { Российская } \\
\text { Федерация }\end{array}$ & $\begin{array}{c}\text { Волгоградская } \\
\text { область }\end{array}$ & $\begin{array}{c}\text { Место } \\
\text { в рейтинге }\end{array}$ \\
\hline $\begin{array}{l}\text { Удельный вес домохозяйств, имеющих доступ к широкополосно- } \\
\text { му Интернет, \% к численности домохозяйств }\end{array}$ & 71,0 & 75,0 & 15 \\
\hline $\begin{array}{l}\text { Удельный вес населения, когда-либо пользовавшегося Интерне- } \\
\text { том, в общей численности населения в возрасте 15-72 лет, \% }\end{array}$ & 81,0 & 79,0 & $40-45$ \\
\hline $\begin{array}{l}\text { Удельный вес населения, использующего Интернет для заказов } \\
\text { товаров и услуг, в общей численности населения в возрасте 15- } \\
\text { 72 лет, \% }\end{array}$ & 23,1 & 23,1 & $32-34$ \\
\hline $\begin{array}{l}\text { Удельный вес населения, использовавшего Интернетом, в числе } \\
\text { получателей электронных государственных и муниципальных ус- } \\
\text { луг за последний год, \% }\end{array}$ & & \\
\hline
\end{tabular}

Примечания. Составлено по: [Абдрахманова и др. 2017, 258-268].

Таблича 4

Тенденции развития электронного правительства в Волгоградской области по некоторым показателям информационного общества

\begin{tabular}{|c|c|c|c|}
\hline \multirow[t]{2}{*}{ Индикаторы развития информационного общества } & \multirow{2}{*}{$\begin{array}{c}\text { Российская } \\
\text { Федерация } \\
\text { (2016 г.) }\end{array}$} & \multicolumn{2}{|c|}{$\begin{array}{c}\text { Волгоградская } \\
\text { область }\end{array}$} \\
\hline & & 2015 г. & 2016 г. \\
\hline Население, взаимодействовавшее с органами государственной власти & 56,1 & 52,2 & 69,3 \\
\hline $\begin{array}{l}\text { В том числе: } \\
\text { через Интернет (официальные сайты и порталы государственных и } \\
\text { муниципальных услуг) }\end{array}$ & 28,8 & 17,3 & 31,2 \\
\hline через МФЦ & 11,8 & 9,3 & 19,6 \\
\hline лично & 22,5 & 31,2 & 38,8 \\
\hline Удельный вес населения, имеющего личную электронную подпись & 4,3 & 0,8 & 1,4 \\
\hline Удельный вес населения, зарегистрированного на ЕПГУ & 22 & 3,8 & 8,1 \\
\hline
\end{tabular}

Примечания. Составлено по: [Абдрахманова и др. 2017, 155-160]. 
ализации электронного правительства) [Бершадская 2013], в то время как аспекты социального участия (уровень компетенций, востребованность услуг, мотивация пользователей электронных услуг) считаются менее важными.

Тем не менее, несмотря на издержки жесткого мобилизационного управления, проблемы формирования информационной инфраструктуры и перехода к электронным государственным и муниципальным услугам были решены в относительно короткие сроки: по показателям индекса развития электронного правительства всего за 9 лет, в период с 2005 по 2014 г., РФ поднялась с 58-го на 27-е место.

Последовавшее вслед за этим снижение рейтинговых значений (35-е место в 2016 г.) указывает на более высокий уровень межстрановой конкуренции при переходе к цифровой экономике и ориентирует на изменение управленческой стратегии с учетом общих тенденций развития структуры и показателей оценки электронного правительства. Ценности цифрового электронного правительства связаны с развитием и совершенствованием информационной среды в целях устойчивого экономического роста и достижения общественного блага (принципов равного доступа, обеспечения новых форм занятости и реализации предпринимательских инициатив на основе конвертации компетенций, умений и навыков в экономике знаний). Приоритеты управленческой стратегии, в свою очередь, связываются с инициированием инноваций - множества локальных проектов, основанных на сетевой коммуникации, партисипативном управлении и стейкхолдерском взаимодействии.

Насколько представлены указанные элементы в современных практиках управления и действия? Результаты проведенного исследования указывают, что новые институциональные ценности не проявляются в управленческих решениях регионального уровня, но присутствуют в оценках, связанных с определением преимуществ электронного правительства, а также в некоторых новых элементах информационной среды.

Результаты анкетирования по использованию услуг портала «Госуслуги.ру», проведенного в 2015 и 2017 г., позволяют говорить о тенденции роста численности пользовате- лей портала, особенно среди молодежи (опрос населения Волгограда показал, что 65 \% респондентов пользовались такими услугами в 2015 г., опрос студентов в 2017 г. показал, что охват числа пользователей портала среди этой категории составил почти 100 \%). Были выявлены также следующие тенденции изменения социального участия: расширение спектра услуг; зависимость запросов на услуги от уровня развития электронных сервисов; повышение требований к техническим стандартам услуг (предоставление услуг полностью в дистанционном режиме); преобладание позитивных установок в отношении электронного правительства; ориентация на потребительские (экономия времени и доступность услуг), а не социально-управленческие стандарты (прозрачность, антикоррупционность и т. д.) его оценки [Васильева, Гаврилова 2017].

Анализ информационных ресурсов и качества информационной среды регионального электронного правительства показал следующие особенности.

1. В проектах государственного электронного правительства используется электронное взаимодействие, определяемое функциональными рамками административных регламентов и включающее возможности влияния на действия управляющих структур (использование форматов обратной связи - регистрационных форм, писем и обращений через личный кабинет, участия в мониторинге качества услуг). В целом развитие электронного правительства ориентировано на информирование, улучшение качества услуг на основе развития электронных сервисов, а также на предоставление дополнительных услуг.

2. Возможности партисипативного участия представлены отдельными акциями, которые реализуются в рамках социального проекта или специального предложения, размещаемого на сайтах НКО. Кроме того, реализуются акции, связанные с обсуждением и принятием какого-либо значимого управленческого решения или закона в рамках специально открытых тематических форумов, размещаемых в форме баннерной ссылки на официальных сайтах органов власти и управления (такой подход, например, использовался при принятии социального кодекса Волгоградской 
области). В целом в информационной инфраструктуре возможности общественной дискуссии представлены институциональной медиасредой, а не другими типами структур.

3. Возможности сетевой коммуникации в деятельности регионального электронного правительства практически не используются (отсутствует мобильная рассылка, сетевой маркетинг, новостные рассылки, взаимодействие с медиасредой и блогосферой), отсутствуют тематические форумы и возможности подписки. Следует отметить, что данные проблемы компенсируется развитием негосударственных информационных сетевых проектов, в том числе социальными сетями и новыми медиа, которые, однако, слабо интегрированы в институциональную инфраструктуру «официального» электронного правительства. Например, в Волгограде начал работать один из немногих проектов, направленных на партисипативное участие, - проект «Яндекс. Мой двор». Кроме того, успешно развиваются несколько негосударственных проектов, направленных на защиту прав граждан.

\section{Выводы исследования}

В целом развитие электронного правительства в Волгоградской области отвечает стандартам стратегии «правительство для населения» и осуществляется в рамках общефедеральной программы развития информационного общества и цифровой экономики. Основными приоритетами развития являются создание информационной инфраструктуры для предоставления электронных услуг, находящихся в ведении органов региональной исполнительной государственной власти и муниципалитетов, и информирование населения по всем вопросам социального взаимодействия и развития. Практические результаты состоят в создании и поддержке регионального портала государственных и муниципальных услуг, официального портала Губернатора и Администрации Волгоградской области, а также целого ряда электронных сервисов, обеспечивающих предоставление электронных услуг.

Особенности внедрения электронного правительства связаны: с мобилизационным типом внедрения социально-управленческих инноваций; преимущественным развитием государственного электронного управления; доминированием процессов «вертикальной интеграции» над «горизонтальной связанностью». Развитие электронного правительства в целом в общественном мнении оценивается положительно, при этом ведущие критерии его оценки задаются потребительскими пользовательскими стандартами и не связываются с институциональными ценностями «рационального управления» или «общественного блага».

Основные проблемы регионального электронного правительства связаны с ограниченностью сферы его действия: «правительство для бизнеса» только начинает формироваться, а правительство для граждан и НКО осознается скорее как идея, а не институциональная ценность и тем более не как технология. Можно предположить, что перспектива проектов регионального электронного правительства будет определяться управленческой стратегией, ориентированной на развитие равных возможностей доступа и развитие элементов информационной среды, связанной с партисипативным участием.

\section{ПРИМЕЧАНИЕ}

1 Исследование выполнено при финансовой поддержке РГНФ в рамках проекта «Технология электронного правительства в системе государственных и муниципальных услуг Волгоградской области: социально-правовое обеспечение эффективной реализации» (№ 16-13-34025 a(p), 20162017 гг, рук. Д.В. Кононенко).

The study was supported by the Russian Humanitarian Science Foundation within "Technology of E-Government in the System of State and Municipal Services of Volgograd Region: Social and Legal Support for Effective Implementation" project (no. 1613-34025 a(p), 2016-2017, under the supervision of D.V. Kononenko).

\section{СПИСОК ЛИТЕРАТУРЫ}

Абдрахманова и др. 2017 - Абдрахманова Г.И., Гохберг Л.М., Кевеш М.А. и др. Индикаторы цифровой экономики: 2017: стат. сб. М.: НИУ ВШЭ, 2017. 
Акаткин, Дрожжинов, Конявский 2014 - Акаткин Ю.М., Дрожжинов В.И., Конявский В.А. Электронное правительство России как система систем // Информационное общество. 2014. Вып. 4. С. 63-76.

Бершадская 2013 - Бериадская Л.А. Акторно-сетевая модель электронного правительства в Российской Федерации (по результатам экспертного опроса) // Власть. 2013. № 3. С. 40-43.

Борисова 2014 - Борисова А.С. Аналитическая оценка развития электронного правительства регионов России на основе системнофункционального подхода // Актуальные проблемы экономики и права. 2014. № 1 (29). C. 94-102.

Васильева, Гаврилова 2017 - Васильева Е.Г., Гаврилова Т.Ф. Переход к предоставлению государственных и муниципальных услуг в Волгоградской области в электронном виде: статистика процесса // Технология электронного государства (правительства): социально-правовое обеспечение эффективной реализации : коллектив. моногр. Волгоград: Волгогр. науч. изд-во, 2017. С. 110-125.

Васильева, Кононенко 2017 - Васильева Е.Г., Кононенко Д.В. Концепция электронного государства (электронного правительства) на текущем этапе общественного развития // Технология электронного государства (правительства): социально-правовое обеспечение эффективной реализации : коллектив. моногр. Волгоград: Волгогр. науч. изд-во, 2017. С. 8-18.

Данилина, Багратуни 2015 - Данилина М.В., Багратуни К.Ю. Актуальные аспекты развития электронного правительства в России // Наука и бизнес: пути развития. 2015. № 5 (47). С. 148-149.

Лайкам и др. 2017 - Лайкам К.Э., Абдрахманова Г.И., Гохберг Л.М., Дудорова О.Ю. и др. Информационное общество в Российской Федерации : стат. сб. М.: НИУ ВШЭ, 2017.

Калинина, Шевандрин 2012 - Калинина А.Э., Шевандрин А.В. Формирование элементов электронного правительства в органах местного самоуправления муниципальных образований // Власть. 2012. № 12. С. 17-21.

Павлюченкова 2013 - Павлюченкова М.Ю. Электронное правительство в России: концептуальные подходы и практика реализации // Politbook. 2013. № 2. C. 90-106.

Постановление Главы Администрации Волгоградской области от 26.10.2011 ... web - Постановление Главы Администрации Волгоградской области от 26.10.2011 № 1166 «Об утверждении Концепции информатизации Волгоградской области (2011-2014 годы)» // http://docs.cntd.ru/document/424068382.
Постановление Правительства Волгоградской области от 27.05.2013 ... web - Постановление Правительства Волгоградской области от 27.05.2013 № 245-п «Об утверждении типового перечня муниципальных услуг, предоставление которых осуществляется по принципу “одного окна” в многофункциональных центрах предоставления государственных и муниципальных услуг» // http://docs.cntd.ru/document/460270508.

Пясецкая 2017 - Пясецкая Е.Н. Электронное правительство и электронная демократия: институциализация политики информационного развития [Концепт. 2017. Сент. (№ 9). С. 98-105]// http://e-koncept.ru/2017/173007.htm.

Россия... web - Россия в рейтинге развития ИКТ: 2016 [Наука. Технологии. Инновации: Экспресс-информация. 30.11.2016] // https:// www.researchgate.net/publication311187131_ Rossia_v_rejtinge_razvitia_IKT_2016.

Bannister, Connolly $201 \overline{2}$ - Bannister $\bar{F}$., Connolly $R$. Defining E-Governance// E-Service Journal. 2012. Vol. 8, № 2, p. 3-25. DOI: 10.2979/eservicej.8.2.3.

Framework... 2012 - Framework for a Set of eGovernment Core Indicators. United Nations Economic Commission for Africa. Technical Specifications of Proposed e-Government Indicators (March 2012) // https://www.itu.int/ en/ITU-D/Statistics/Documents/partnership/ Framework_for_a_set_of_E-Government Core_Indicators_Final_rev1.pdf.

Palvia, Shärma web - Palvia S.C.J., Sharma S.K. E-Government and E-Governance: Definitions [Domain Framework and Status Around the World, Comput. Soc. India, International Conference on E-Governance. 2007. P. 1-12] // http://www.csi-sigegov.org/1/1_369.pdf.

Porwol, Ojo, Breslin 2016 - Porwol L., Ojo A., Breslin J.G. An Ontology for Next Generation e-Participation Initiatives // Government Information Quarterly. 2016. Vol. 33, № 3. P. 583594. DOI: 10.1016/j.giq.2016.01.007.

Sakowicz web - Sakowicz M. How to Evaluate E-Government? [Different Methodologies and Methods. In Eleventh NISPAAnnual Conference, Romania. 2003] // http://unpan1.un.org/intradoc/ groups/public/documents/NISPAcee/ UNPAN009486.pdf.

The United Nations... web - The United Nations E-Government Survey 2016 [E-Government in Support of Sustainable Development. N. Y.: Department of Economic and Social Affairs] // http:/ /workspace.unpan.org/sites/Internet/Documents/ UNPAN97453.pdf.

World Development Report... 2016 - World Development Report 2016: Digital Dividends. Washington, DC: World Bank. 


\section{REFERENCES}

Abdrakhmanova G.I., Wisniewski, K.A., Volkov G.L., Gokhberg L.M. et al. (ed.), 2017. Indicators of the digital economy: 2017: statistical collection. Moscow, National Research University "Higher School of Economics".

Akatkin Yu.M., Drozhzhinov V.I., Konyavskiyi V.A., 2014. Information Society Russian, E-Government as the System of Systems. Information Society, Iss. 4, pp. 63-76.

Bershadskaya L.A., 2013. Actor-Network Model of E-Government in the Russian Federation. The Authority, no 3, pp. 40-43.

Borisova A.S., 2014. Analitical Estimation of Electronic Government Development in the Russian Regions Basing on Systemic-functional Approach. Actual Problems of Economics and Law, no. 1 (29), pp. 94-102.

Vasileva E.G., Gavrilova T.F., 2017. The Transition to Providing state and municipal services in the Volgograd region in the statistics of the process. E-Government technology: social and legal support for effective implementation. Volgograd, Volgograd scientific publishing house, pp. 110-125.

Vasileva E.G., Kononenko D.V., 2017. The concept of public e-Government and e-Government in modern social development. E-Government technology: social and legal support for effective implementation. Volgograd, Volgograd scientific publishing house, pp. 8-18.

Danilina M.V., Bagratuni K.Yu., 2015. Topical Issues of E-Government Development in Russia. Science and Business: Ways of Development, no. 5 (47), pp. 148-149.

Laikam K.E., Abdrakhmanova G.I., Gokhberg L.M., Dudorova O.Yu. et al., 2017. Information society in the Russian Federation: statistical collection. Moscow, National Research University "Higher School of Economics".

Kalinina A.E., Shevandrin A.V., 2012. Formation of the Elements ofE-Government in Local Self-Government Bodies. The Authority, no. 12, pp. 17-21.

Pavlyutenkova M.Yu., 2013. Russian Electronic Government: Conceptual Approaches and Practice of Realization. Politbook, Vol. 26, no. 2, pp. 90-106.

Resolution of the Head of Administration of the Volgograd region of October 26, 2011 no. 1166 "About the approval of the Concept of Informatization of the Volgograd region (20112014)'. URL: http://docs.cntd.ru/document/ 424068382 (accessed 20 January 2019).
Resolution of the Government of the Volgograd region of 27.05.2013 no. 245-p "About the approval of the standard list of municipal services which providing is performed on the principle of "one window" in the multipurpose centers of providing the state and municipal services", 2013. URL: http://docs.cntd.ru/document/ 460270508 (accessed 20 January 2019).

Pyasetskaya E.N., 2017. E-Government and E-Democracy: the institutionalization of information policy development. Concept, no. 9, pp. 98-105.

Russia in the rating of ICT development: 2016. Science. Technologies. Innovation: Express information. 30.11.2016. Moscow, National Research University "Higher School of Economics". URL: https:// www.researchgate.net/publication/ 311187131_Rossia_v_rejtinge_razvitia_IKT_2016 (accessed 20 January 2019).

Bannister F., Connolly R., 2012. Defining E-Governance. E-Service Journal, Vol. 8, no. 2, pp. 3-25. DOI: 10.2979/eservicej.8.2.3.

Framework for a set of e-government core indicators. United Nations Economic Commission for Africa. Technical specifications of proposed egovernment indicators (March 2012). URL: https://www.itu.int/en/ITU-D/Statistics/ Documents/partnership/Framework for_a_set_of_E-Government_Core_Indicators Final_rev1.pdff(accessed 20 January 2019).

Palvia S.C.J., Sharma S.K., 2007. E-Government and E-Governance: Definitions. Domain Framework and Status around the World, Comput. Soc. India, International Conference on E-Governance, pp. 112. URL: http://www.csi-sigegov.org/1/1_369.pdf (accessed 20 January 2019).

Porwol L., Ojo A., Breslin J.G., 2016. An ontology for next generation e-Participation initiatives. Government Information Quarterly, Vol. 33, no. 3, pp. 583-594. DOI: 10.1016/j.giq.2016.01.007.

Sakowicz M. How to Evaluate E-Government? Different Methodologies and Methods, In Eleventh NISPA Annual Conference, Romania, 2003. URL: http://unpan1.un.org/ intradoc/groups/public/documents/NISPAcee/ UNPAN009486.pdf(accessed 20 January 2019).

The United Nations E-Government Survey 2016: E-Government in Support of Sustainable Development. N. Y., Department of Economic and Social Affairs. URL: http://workspace.unpan.org/ sites/Internet/Documents/UNPAN97453.pdf.

World Development Report 2016: Digital Dividends. Washington, DC, World Bank. URL: wwwwds.worldbank.org (accessed 20 January 2019). 
Е.Г. Васильева. Между технологией и институтами: особенности формирования электронного правительства

\section{Information about the Author}

Elena G. Vasileva, Candidate of Sciences (Philosophy), Associate Professor, Department of Sociology, Volgograd State University, Prosp. Universitetsky, 100, 400062 Volgograd, Russian Federation, vasilievaeg@yandex.ru, socpol@volsu.ru,https://orcid.org/0000-0002-5113-4071

\section{Информация об авторе}

Елена Геральдовна Васильева, кандидат философских наук, доцент кафедры социологии, Волгоградский государственный университет, просп. Университетский, 100, 400062 г. Волгоград, Российская Федерация, vasilievaeg@yandex.ru, socpol@volsu.ru, https://orcid.org/0000-0002-5113-4071 